\title{
RETORNOS DAS AÇÕES E O LUCRO: AVALIAÇÃO DA RELEVÂNCIA DA INFORMAÇÃO CONTÁBIL.
}

\author{
STOCK RETURNS AND PROFIT: ASSESS THE RELEVANCE OF \\ ACCOUNTING INFORMATION.
}

\author{
Octávio Valente Campos ${ }^{a}$; Wagner Moura Lamounier ${ }^{b}$; Valéria Gama Fully Bressan ${ }^{c}$ \\ ${ }^{a}$ Mestre em Ciências Contábeis pela Universidade Federal de Minas Gerais, UFMG; \\ Belo Horizonte, $M G$-Brasil; E-mail: octaviovc@yahoo.com.br \\ ${ }^{b}$ Professor da Universidade Federal de Minas Gerais, UFMG;

\section{Resumo}

Este artigo objetiva verificar, através do teste de causalidade de Granger, o relacionamento entre as séries trimestrais dos lucros contábeis e os retornos de mercado (RET) de empresas brasileiras com ações em bolsa que apresentam níveis diferentes de exigências de divulgação. A amostra analisada foi composta por 75 empresas listadas na BM\&FBOVESPA, durante o período de 1995 à 2010 . As variáveis analisadas foram os retornos contábeis (ROE) e os retornos de mercado (RET). Na análise dos resultados, verificou-se, ao nível de 5\% de significância estatística, que boa parte das empresas apresentou pelo menos algum sentido de causalidade, ou do ROE para o RET, ou do RET para o ROE. Foi averiguado também, pela análise em nível agregado dos P-valores do teste de Granger, que há bicausalidade entre ROE e RET, concluindo-se que o mercado brasileiro de ações não possui eficiência de mercado na amostra analisada. Destaca-se, dentre os principais resultados desta pesquisa, que não foi constatado que a causalidade entre ROE e RET é maior para empresas que possuem maior nível de exigência de divulgações das informações contábeis, permitindo inferir que os lucros líquidos das empresas que divulgam mais informações contábeis não possuem maior causalidade com o retorno de mercado do que as demais empresas. Com isso, pode-se concluir de forma geral, que apesar da importância das informações contábeis para o mercado de ações, a maior qualidade e quantidade destas informações não geraram maior capacidade preditiva dos retornos do mercado.

Palavras-chave: Retorno das ações; Informação contábil; Causalidade de Granger.

\begin{abstract}
This article aims to verify, by testing for Granger causality, the relationship between sets of quarterly accounting earnings and market returns (RET) of Brazilian on the market that have different levels of disclosure requirements. The sample was composed of 75 companies listed on BOVESPA during the period 1995 to 2010, who had 15 consecutive observations and synchronous returns accounting (ROE) and market return (RET), reducing thus the survival bias in these series. In analyzing the results, it was found at the $5 \%$ level of statistical significance which most companies had at least some sense of causality, or ROE for the RET, or RET for the ROE. It was also ascertained by analysis at the aggregate level of P-values of the Granger test, which is bi-causality between ROE and RET, concluding that the Brazilian stock market has market efficiency in the sample. It stands out among the main results of this research, which was not found that the causality between ROE and RET is higher for companies that have a higher level of required disclosures of accounting information, allowing to infer that the net profits of companies that disclose more information statements do not have more causality to the market return than other firms. Therefore, we may conclude generally, that despite the importance of accounting information for the stock market, the highest quality and quantity of the information did not generate greater predictive ability of market returns.
\end{abstract}

Keywords: Stock returns; Accounting information; Granger Causality. 


\section{INTRODUÇÃO}

A pesquisa em contabilidade financeira, depois da mudança de paradigma derivada dos trabalhos de Ball e Brown (1968) e Beaver (1968), passou a investigar como e quando o mercado de ações reage às informações contábeis, interessando tanto ao público preocupado com as normas contábeis quanto aos usuários interessados na eficiência dos mercados financeiros.

Especificamente, o grupo de usuários interessados pelas normas contábeis procura saber se os dados contábeis concedem informações relevantes para os investidores tomarem suas decisões de investimento. E, pontualmente, quais informações contábeis conferem maior utilidade para este fim. Já os interessados na eficiência de mercado procuram verificar se os ativos financeiros estão sendo contabilmente mensurados pelo mesmo valor que o mercado concede (O’HANLON, 1991).

Quando a contabilidade supre a necessidade de ambos os grupos de usuários, gerando informações relevantes e tempestivas, fica evidente sua importância para a economia como um todo, pois desta forma os ativos serão corretamente mensurados, evitando sub-alocação de recursos. Por isso, pesquisas como a realizada neste artigo, buscam identificar aspectos que auxiliam a interpretação dos dados divulgados, gerando maior capacidade de predição, o que contribui, portanto, para toda a economia.

Desde a mudança do paradigma supracitado, que a técnica de "estudo de eventos" vem comumente sendo utilizada para pesquisas com essas necessidades, auxiliando a constatar a existência de retornos excessivos, ou seja, se os mesmos apresentam-se acima do esperado nas proximidades do evento, permitindo assim avaliar o nível de eficiência do mercado. Alguns trabalhos nacionais que utilizaram esta metodologia foram os de SANTANA (2002), CARVALHO (2003) e BATISTELA et. al. 92004). Já nesta presente pesquisa, uma metodologia alternativa ao estudo de evento foi empregada para se verificar a rapidez e a direção com que as informações são veiculadas pelo mercado financeiro que é a técnica desenvolvida por Granger (1969).

Estudos similares que utilizaram o teste de causalidade de Granger foram realizados tanto no mercado brasileiro quanto mundial, porém, com uma abordagem e uma forma de visão sobre a forma de análise dos dados contábeis que se diferencia do presente estudo, sendo um dos focos deste artigo a comparação e discussão dos resultados obtidos. Entre os principais artigos nacionais cita-se: Costa Jr, Meurer, e Cupertino (2007) - em que usaram o teste de causalidade de Granger; Galdi e Lopes (2008) - em que usaram o teste de causalidade de Granger e de Cointegração; Sonza e Kloeckner (2009) - em que usaram estudo de eventos; e Carvalhal (2010) - em que foi usado o teste de causalidade de Granger. E as principais pesquisas em outros mercados são: O’Hanlon (1991); Martikainen e Puttonen (1993); e Jindrichovska (2001) - em que ambos usaram o teste de causalidade de Granger.

É importante também verificar a possível diferença de comportamento entre as informações contábeis em relação aos retornos das ações para empresas com tipos diferentes de exigência de divulgação de suas informações, assim como ocorre em seguimentos distintos representados pelo Novo Mercado e Mercado Tradicional existentes na BM\&FBOVESPA. De acordo com o site da BM\&FBOVESPA, o Novo Mercado é um segmento de listagem destinado à negociação de ações emitidas por companhias que se comprometam, voluntariamente, com a adoção de práticas de governança corporativa adicionais ao que é exigido pela legislação. Assim, a valorização e a liquidez das ações são influenciadas positivamente pelo grau de segurança oferecido pelos direitos concedidos aos acionistas e pela qualidade das informações 
prestadas pelas companhias. Já o Mercado Tradicional é composto pelas empresas que não se comprometem a adotar práticas de governança corporativa adicionais ao que é exigido pela legislação. Essa diferença demonstra que as informações contábeis das empresas listadas no Novo Mercado possuem maior qualidade para os usuários, o que pode ser significante para a capacidade de previsão dos retornos das ações das empresas que estão neste segmento. Desta forma, é imperativo identificar se o maior nível de divulgação das informações financeiras e econômicas ocasionam em diferenças significativas quando se busca relacionar informações derivadas de demonstrativos financeiros para prever os retornos das ações.

Especificamente em Galdi e Lopes (2008) os autores afirmam que os países com características menos ortodoxas (contabilidade direcionada por princípios e não por normas) apresentaram maior co-integração entre os retornos contábeis e os preços das ações, indicando que pode haver diferença nos resultados encontrados de acordo com o tipo de contexto contábil, o que é corroborado por Costa, Costa e Lopes (2006). Tomando por base a diferença encontrada por esses autores, buscar-se-á verificar se o nível de exigência sobre as divulgações contábeis tem efeito na causalidade do lucro com os retornos das ações, buscando responder ao seguinte questionamento: Qual é a relação entre o lucro contábil e os retornos das ações em empresas com níveis diferentes de exigências de divulgação?

Para responder o problema de pesquisa, este artigo objetiva verificar o relacionamento entre as séries trimestrais dos retornos sobre o patrimônio (ROE) e os retornos das ações (RET) de empresas brasileiras com ações em bolsa que apresentam níveis diferentes de exigências de divulgação. Como objetivo secundário busca-se verificar qual é a relação de causalidade entre estas variáveis.

Assim, a principal contribuição deste artigo para o tema é a verificação da possível diferença de causalidade entre as informações contábeis e os retornos das ações entre empresas com níveis diferentes de Governança Corporativa, e conseqüentemente, com o nível de informações divulgadas para os usuários externos. Desta forma, será possível verificar qual a hipótese de eficiência de mercado possui a amostra avaliada.

\section{REFERENCIAL TEÓRICO}

\subsection{Hipóteses de Eficiência de Mercado (EMH)}

Fama (1970) apresenta que a Hipótese de Eficiência de Mercado (EMH) tem como princípio o fato de que em mercados eficientes o preço de um ativo reflete consistentemente todas as informações relevantes disponíveis, não havendo a possibilidade de se obter lucros anormais em qualquer uma das formas de mercados eficientes.

Antes da apresentação das formas de EMH, se faz necessário discutir sobre a maneira que será verificada as eficiências de mercado neste estudo. Uma técnica comumente utilizada para pesquisas com essas necessidades é a técnica denominada de "estudo de evento", que visa, essencialmente, verificar se há a existência de retornos anormais, ou seja, os que se apresentam divergentes do esperado nas proximidades dos eventos e o respectivo tempo necessário para que o mercado reaja a uma nova informação relevante. Alguns trabalhos nacionais com esta metodologia são os de Santana (2002); Carvalho, (2003); e Batistela et al, (2004).

No entanto, o uso de séries temporais também pode ser utilizado para se verificar a Eficiência de Mercado. Assim como já citado por Fama (1970), em um mercado eficiente não é 
possível obter lucros anormais. Portanto, neste presente trabalho a análise de séries temporais será utilizada para verificar a eficiência do mercado brasileiro de ações, contribuindo assim para o aprimoramento do conhecimento sobre este assunto abordado.

Adentrando nas formas de EMH, Watts e Zimmerman (1986) argumentam que estas formas de eficiência são segregadas de acordo com o conjunto de informações usadas para testar a eficiência do mercado. Desta forma, eles especificam:

- $\quad$ Forma fraca da Hipótese de Eficiência de Mercado: Assume-se que os preços das ações refletem apenas as informações que estão contidas no histórico passado de preços. Estes dados são prontamente avaliados pelas pessoas interessadas, portanto, não se espera uma sistemática de taxas anormais de retorno nesta hipótese.

Haugen (2001), afirma que, se confirmada a forma fraca de eficiência de mercado, podese dizer que a análise técnica ou gráfica se torna inútil, pois toda informação constante no gráfico já foi analisada por vários técnicos em todo o mercado e retornos expressivos com esse tipo de análise não seriam possíveis. Logo, o preço do ativo financeiro já se consolidou em um nível que reflete toda a informação relevante introduzida nos valores históricos desses preços.

- Forma semi-forte da Hipótese de Eficiência de Mercado: Nesta hipótese os preços das ações refletem todas as informações publicas e relevantes. Estes dados são prontamente avaliados pelas pessoas interessadas, portanto, não se espera uma sistemática de taxas anormais de retornos ao observar esta hipótese.

Neste sentido, Haugen (2001) menciona que toda a informação pública disponível está refletida nos preços dos ativos, incluindo as informações sobre as séries de preços das ações, as demonstrações financeiras da própria empresa, as demonstrações financeiras de empresas competidoras, as informações sobre a economia em geral e qualquer outra informação pública que seja relevante para a avaliação da entidade. Confirmada a forma semi-forte de eficiência de mercado, nenhum tipo de análise fundamentalista baseada em dados públicos será útil para se obter lucros anormais em investimentos.

- $\quad$ Forma forte da Hipótese de Eficiência de Mercado: Assume-se nesta hipótese que os preços das ações refletem todas as informações disponíveis e não disponíveis publicamente no mercado. Isto é, toda a informação relevante está refletida no preço das ações, inclusive informações privadas, confidenciais ou internas à empresa, assim como informações públicas.

Para Haugen (2001), aqueles que adquirem a informação agem com base na mesma, logo suas ações terão reflexos nos preços e estes instantaneamente se ajustarão para refletir as informações privadas. Confirmada essa forma forte de eficiência de mercado, um investidor profissional não tem vantagem no mercado, pois nenhuma forma de procurar ou processar informações privadas produzirá consistentemente retornos anormais. Ou seja, se um mercado apresentar eficiência na forma forte, nem mesmo uma informação privilegiada concederá ao seu detentor a possibilidade de lucros anormais, pois ao estar em posse desta informação e usála no mercado, os demais participantes indiretamente intuirão sobre esta mesma informação, agindo na mesma direção do primeiro, o impossibilitando de obter os ganhos anormais por muito tempo.

Portanto, para o mercado ser eficiente, os preços dos ativos devem responder corretamente e rapidamente à presença de nova informação relevante para a sua mensuração. Com isso, as mudanças em retornos esperados dos ativos de um período para outro devem estar pautadas 
apenas nas mudanças no nível da taxa de juros livre de risco e nas mudanças no nível do risco do prêmio associado ao ativo. Assim, deve ser impraticável em um mercado eficiente, examinando as características de investimentos correntes, diferenciar entre investimentos lucrativos e não lucrativos no futuro. Neste contexto, se for possível separar investidores profissionais de investidores comuns, deve-se concluir que não há uma diferença significativa entre o desempenho médio de investimento dos dois grupos; sendo também insignificantes as diferenças de desempenho de investidores individuais dentro de um mesmo grupo. Isto é, diferenças de desempenho intra ou extra grupos devem ser devidas ao acaso, e não serem sistemáticas e permanentes (HAUGEN, 2001).

No escopo deste artigo, a forma semi forte é a mais adequada para a análise, pois se trabalha com os dados passados do retorno das ações e com valores passados dos lucros disponibilizados pelas demonstrações publicadas. Com isto, este artigo auxilia a compreensão do relacionamento entre o Lucro Contábil e o mercado de ações. Se for verificada a capacidade de previsão dos retornos contábeis através do lucro contábil, fica caracterizado que o mercado estudado é ineficiente.

\subsection{Estudos feitos no Brasil.}

Um estudo importante sobre o assunto em nível nacional foi realizado por Costa Jr, Meurer, e Cupertino (2007). O objetivo desse artigo foi verificar o relacionamento entre as séries trimestrais de retornos contábeis (ROE) e de retornos de mercado (RET) de empresas brasileiras com ações em bolsa através do teste de causalidade de Granger. A amostra foi composta de 97 empresas com ações negociadas na Bovespa durante o período de janeiro de 1995 a março de 2007.

Agregando-se todos os resultados individuais, os resultados dos testes evidenciaram a existência de causalidade na direção do retorno contábil (ROE) para o retorno de mercado (RET) a um nível marginal de $10 \%$, não se verificando nenhuma causalidade, também a nível agregado, na direção do retorno de mercado (RET) para o retorno contábil (ROE). Baseado nisto, os autores concluíram que embora marginalmente, há certa ineficiência no mercado de ações brasileiro frente a publicações de balanços, sendo este resultado similar ao trabalho realizados no Reino Unido, O'Hanlon (1991), que também adotou a metodologia de Granger e será explorado no decorrer do texto.

O trabalho de Sonza e Kloeckner (2009), por meio da análise de co-integração e do Vetor de Correção de Erros, teve como objetivo principal avaliar o equilíbrio de longo prazo e a dinâmica de curto prazo para a relação entre o lucro contábil das empresas e o respectivo preço das ações negociadas pela BM\&FBOVESPA. Na análise dos coeficientes de ajustamento $\alpha$ irrestritos, os resultados indicaram uma velocidade de ajustamento relativamente lenta para o equilíbrio de longo prazo para o lucro e o preço das ações, evidenciando um período de tempo relativamente extenso para estas variáveis atingirem equilíbrio. Após o calculo da velocidade dos coeficientes com a restrição imposta para o $\beta$ do valor das ações igual a 1 , os resultados demonstraram uma velocidade de ajustamento ainda lenta para esta variável, mas o lucro apresentou velocidade de ajustamento significativamente maior, diminuindo o tempo para que as variáveis atinjam equilíbrio de longo prazo.

Pela abordagem econômica, estes resultados mostram que a elasticidade de transmissão do lucro para o preço das ações, na maior parte das empresas, mostrou-se relevante, evidenciando 
que os lucros influenciam consideravelmente o preço das ações a longo prazo. Portanto, o artigo de Sonza e Kloeckner (2009) evidencia, através de análises quantitativas consistentes, a relevância dos dados contábeis para o mercado de capitais, enfatizando as relações de longo prazo existentes no mercado de ações, mostrando que o resultado das empresas influencia substancialmente o preço das ações. O que vai de encontro ao trabalho de Costa Jr, Meurer, e Cupertino (2007) já apresentado.

Estudo similar ao de Costa Jr, Meurer, e Cupertino (2007) foi a recente pesquisa de Carvalhal (2010). Através dos testes estatísticos de causalidade de Granger, esse trabalho teve o objetivo de verificar a relação de causalidade entre o retorno contábil (ROE) e o retorno do mercado de ações (RET) no Brasil das empresas listadas na BM\&FBOVESPA. A mostra foi composta por 93 empresas durante o período de 1995 ao primeiro trimestre de 2009.

Os resultados dos testes indicaram, de forma geral, que não há evidências que tornam possível identificar causalidade entre o RET e o ROE ou vice-versa, não sendo possível apontar nesses casos precedência temporal no período analisado, considerando tanto os níveis de significância de $1 \%$, de $5 \%$ ou de $10 \%$. Isso demonstra o baixo poder de melhoria da previsão com a inclusão de uma das variáveis em análise como uma variável defasada na equação de regressão (CARVALHAL, 2010). Este resultado condiz com o encontrado por Costa Jr, Meurer, e Cupertino (2007).

Outro artigo neste sentido foi o trabalho comparativo realizado por Galdi e Lopes (2008). Esse trabalho teve como objetivo analisar a relação entre o lucro contábil e o preço das ações no mercado latino-americano. Para isso, foi aplicado os testes econométricos de estacionariedade (KPSS), co-integração (Johansen) e causalidade (Granger). Os resultados evidenciaram que existe um relacionamento de longo prazo entre o lucro e os preços das ações para a maior parte das empresas analisadas. Esses resultados são consistentes com os modelos apresentados por Ohlson (1995) e Ohlson e Juettner-Nauroth (2005), que relacionaram o preço da ação com o lucro da empresa. Porém, não se pode estabelecer uma relação de causalidade (de acordo com o conceito de causalidade de Granger) entre essas duas variáveis.

Esse resultado pode ser explicado pela falta de oportunidade do lucro contábil. Costa, Costa e Lopes (2006) mostraram evidências de que o lucro contábil dos países da América do Sul é conservador, o que legitima as evidências encontradas de que quando há relação de causalidade de Granger entre preço e lucro, normalmente ela ocorre do preço para o lucro e não o contrário. Em Galdi e Lopes (2008), houve situações em que se apresentou causalidade do preço para o lucro, em outras demonstrou causalidade do lucro para o preço, porém, na maioria das situações não houve sentido de causalidade em nenhum sentido. Portanto, fica evidente na equação de regressão o baixo poder de melhoria da previsão com a inclusão de uma das variáveis em análise como uma variável exógena defasada.

\subsection{Estudos realizados em outros países.}

Um dos estudos pioneiros que utilizou o teste de Causalidade de Granger para verificar a relação entre lucro e informações contábeis é o de Bar-Yosef, Callen e Livnat (1983). O objetivo deste trabalho foi testar empiricamente as relações entre lucro e investimento das empresas. Foi investigado, através do teste de causalidade Granger, se os valores defasados dos investimentos melhoram a predição de lucros futuros do que apenas previsões que são baseados somente nos lucros defasados. Os resultados empíricos mostraram que as séries 
bivariadas de lucros e investimentos foram superiores à serie univariada para prever os investimentos futuros, mas não na previsão de lucros futuros. A amostra foi composta pelos dados anuais industriais dos EUA limitadas àquelas empresas que apresentavam as informações necessárias nos anos de 1960 a 1981, totalizando-se 644 empresas.

Outro importante artigo, muito citado na literatura sobre o tema é o de O'Hanlon (1991). Através de uma amostra de 222 empresas do Reino Unido com os dados anuais obtidos dos anos de 1968 à 1987, o objetivo deste artigo foi verificar, por meio da causalidade de Granger, se os retornos contábeis causam os retornos nas ações, ou vice-versa. Os resultados evidenciaram que há casualidade bidirecional entre as variáveis e quando avaliado qual variável causa mais a outra - por meio da análise agregada dos p-valor de cada empresa obtido no teste de causalidade de Granger - foi demonstrado que o retorno contábil causa mais fortemente o retorno nas ações do que o contrário. Esse trabalho de O'Hanlon (1991) sugere a realização do mesmo tipo de pesquisa em outros mercados para ser feita comparações, o que foi feito neste presente artigo, e em demais já citados e a serem citados.

Seguindo esta sugestão, Martikainen e Puttonen (1993) realizaram o mesmo tipo de estudo no mercado finlandês com a amostra de 21 empresas com dados anuais no periodo de 1974 à 1989. Os resultados sugeriram que os retornos das ações causam os retornos contábeis e não o contrátio. Com isso, apesar da pequena amostra, os autores concluiram que o mercado finlandês antecipa o sucesso futuro das empresas. Este resultado encontrado é oposto ao encontrado por O’Hanlon (1991).

$\mathrm{Na}$ mesma linha de raciocínio, porém com uma metodologia diferente baseada em estudos de eventos, Jindrichovska (2001) fez uma pesquisa na República Tcheca que é um mercado emergente. O objetivo deste trabalho foi testar a existência de relação estatisticamente significante entre o lucro contábil e o retorno das ações. A amostra foi comporta por 63 empresas industriais de capital aberto durante os anos de 1993 à 1998. Como principal conclusão o autor evidenciou a existência de relação entre estas variáveis para medições de um ano ou mais.

Ainda em mercado emergente, Mahmood e Fatah (2007) estudaram a relação entre retorno das ações, os rendimentos de dividendos e o retorno de lucro no mercado da Malásia. O objetivo foi examinar a existência de relação de curto e longo prazo e o poder preditivo (causalidade) entre o retorno das ações, rendimentos dos dividendos e retornos de lucro. Através de dados mensais dos anos de 1989 à 2005 estes autores concluíram que existe relação muito forte entre as variáveis. O teste de causalidade evidenciou que tanto o rendimento de dividendos quanto o retorno do lucro causa Granger (prevê) o retorno das ações. Acontece também a causalidade de Granger no sentido dos retornos das ações e retorno de lucro prevendo o rendimento de dividendos, bem como o retorno das ações e rendimento dos dividendos prevendo o retorno dos lucros. Desta forma, verifica-se que no mercado da Malásia, todas estas variáveis são importantes para se fazer predições.

\section{HIPÓTESES}

Com base nos estudos já realizados sobre o tema, e sobre as características necessárias para uma empresa se enquadar no seguimento do Novo Mercado, tem-se a seguinte hipótese:

$H 0$ : As empresas do Novo Mercado apresentam maior causalidade no sentido do ROE para o 
RET do que as demais empresas.

E, como em outros estudos realizados em outras amostras verificou-se que as variáveis analisadas se influênciam mutuamente, tem-se a seguinte hipótese:

H0: A relação de causalidade entre ROE e RET para toda a amostra é bidirecional.

\section{METODOLOGIA}

\subsection{O teste de causalidade de Granger.}

Anteriormente à discussão sobre o teste de causalidade é fundamental a discussão sobre a estacionariedade das séries. A estacionariedade é uma condição vital para a análise de séries de tempo. Séries não-estacionárias não são passíveis de modelagem dentro da estrutura clássica de séries de tempo. As premissas do modelo de regressão clássico necessitam que tanto a variável explicada quanto as variáveis explicativas sejam estacionárias, com os resíduos possuindo média zero e variância constante. Regressões envolvendo dados de séries temporais não estacionárias incluem grande possibilidade de se obter resultados duvidosos ou espúrios, isto é, de modo superficial, os resultados podem parecer confiáveis e relevantes, porém, depois de investigações adicionais, eles apresentam características suspeitas (GUJARATI, 2006).

Para verificar a existência de estacionariedade das séries será utilizado, usando o nível de significância estatística de 5\%, o teste da raiz unitária denominado Dickey-Fuller aumentado (ADF). Para as séries que não tiverem significância estatística será realizada, primeiramente, a regressão da série (variável explicada) em relação ao tempo (variável explicativa), obtendo os resíduos desta regressão, que de acordo com Gujarati (2006), não será estacionária. Se esses resíduos não apresentarem estacionaridade de acordo com o teste da raiz unitária, será feita a primeira diferença da série $-\Delta \mathrm{Xt}=(\mathrm{Xt}-\mathrm{Xt}-1)$ - transformando a série em estacionária. Utilizarse-á, portanto, para as séries não estacionárias, os resíduos da regressão ou a primeira diferença para os testes de causalidade de Granger.

O teste de causalidade foi desenvolvido por Granger (1969), pois, segundo ele, ocorre em algumas ocasiões uma dificuldade em decidir a direção da causalidade entre duas variáveis relacionadas e também se está ou não ocorrendo feedback entre elas. Gujarati (2006, p. 559, 560) complementa ao afirmar que "embora a análise de regressão lide com a dependência de uma variável em relação a outras, isso não implica necessariamente causalidade". Ou seja, "a existência de uma relação entre variáveis não prova causalidade nem direção de influência".

Segundo Pindyck e Rubinfeld (2004) este teste se baseia em uma idéia simples. Se X causa $Y$, então variações em X devem preceder variações em $Y$. Para dizer que " $X$ causa $Y$ " é necessário cumprir duas condições: a) $\mathrm{X}$ deve ajudar a prever $\mathrm{Y}$. Isto é, em uma regressão de $\mathrm{Y}$ em relação aos seus valores defasados, o acréscimo de valores defasados de $\mathrm{X}$ como variável independente deve contribuir significantemente para aumentar o poder explicativo da regressão. b) Y não deve ajudar a prever $\mathrm{X}$, pois se $\mathrm{X}$ ajuda a prever $\mathrm{Y}$ e $\mathrm{Y}$ ajuda a prever $\mathrm{X}$, provavelmente uma ou mais variáveis estão de fato "causando" as mudanças observadas nestas duas variáveis.

Contrariando a letra "b" citada anteriormente por Pindyck e Rubinfeld (2004), Gujarati (2006) insere a casualidade bidirecional como uma das formas de casualidade, em que ocorre quando tanto o coeficiente $\mathrm{X}$ quanto o coeficiente $\mathrm{Y}$ são estatisticamente diferentes de zero nas duas regressões. Como outros trabalhos semelhantes também consideram a casualidade 
bidirecional, este artigo também o considerará, pois como o objetivo é aumentar o poder de previsão com as variáveis estudas, não está no escopo do presente estudo avaliar as outras variáveis que podem estar influenciando nas causalidades observadas.

Para avaliar estas condições, através do um teste F, testa-se a hipótese nula de que uma variável não ajuda a prever a outra. Portanto, usando a soma de quadrados dos resíduos de cada regressão para calcular a estatística $F$, é testado se o grupo dos coeficientes $\beta$ s é significativamente diferente de 0 (zero). Sendo diferente de 0 (zero), rejeita-se a hipótese nula, ou seja, X causa Y. (PINDYCK e RUBINFELD, 2004).

Formalmente, o modelo é testado pela estimação das seguintes regressões:

$$
\begin{aligned}
& X_{t}=\sum_{i=1}^{n} a_{i} Y_{t}-i+\sum_{j=1}^{n} b_{j} X_{t-j}+\epsilon_{t} \\
& Y_{t}=\sum_{i=1}^{n} c_{i} X_{t}-1+\sum_{j=1}^{n} d_{j} Y_{t-j}+\varphi_{t}
\end{aligned}
$$

Em que a hipótese nula é $H_{0 x}: \Sigma_{a i}$ para a primeira equação e $H_{0 y}: \Sigma_{\mathrm{ci}}$ para a segunda. Com isso, verifica-se que o objetivo proposto por Granger (1969) foi alcançado, que é o de esclarecer as relações entre certos modelos econométricos para verificar a causalidade e feedback entre as variáveis.

De acordo com Pindyck e Rubinfeld (2004), a estatística do teste F é formalmente dada como:

$$
F=(N-k) \frac{\left(S Q R_{R}-S Q R_{U R}\right)}{q\left(S Q R_{U R}\right)}
$$

Em que:

$$
\begin{aligned}
& S Q R_{R} \text { é a soma de quadrados dos resíduos da regressão restrita } \\
& Y_{t}=\sum_{j=1}^{n} d_{j} Y_{t}-j+\varphi t \\
& \quad ; \\
& \sum_{i=1}^{n} C_{i R} X_{t}-1+\sum_{j=1}^{n} d_{j} Y_{t}-j+\varphi t
\end{aligned}
$$

$k$ é o número de parâmetros estimados na regressão irrestrita; e

$q$ é o número de restrições de parâmetros.

Neste estudo realizou-se o teste de Granger com uma (1), duas (2), três (3) e quatro (4) defasagens, sendo demonstrado, nos resultados encontrados (Tabela 1), em qual defasagem o P-valor do teste de Granger apresentou menor valor, ou seja, em qual defasagem as variáveis apresentaram maior relação de causalidade para cada empresa.

\subsection{Amostra}

As séries temporais trimestrais foram obtidas através do banco de dados do Economática ${ }^{\circledR}$ 
para as empresas que apresentaram ações negociadas na BM\&FBOVESPA no período compreendido entre Março de 1995 a setembro de 2010. Este período de tempo foi escolhido devido à estabilização econômica do Brasil após o Plano Real. Dessas empresas foram coletados os dados do Lucro Líquido, do Patrimônio Líquido e do valor de fechamento das ações em cada trimestre. A princípio, a amostra ficou composta 531 empresas, porém, como não foram encontrados os dados sobre Lucro Líquido, de Patrimônio Líquido e do preço das ações para todas as empresas ao longo do período analisado, eliminou-se da amostras as empresas em que não se conseguiu calcular pelo menos 15 observações consecutivas e sincrônicas de retornos contábeis (ROE) e os retornos de mercado (RET). Desta forma, a amostra total foi reduzida a 75 empresas (o que representa 14,15\% de todas as empresas listadas na BM\&FBOVESPA). Com este procedimento procurou-se minorar o viés de sobrevivência pelo fato de existir na amostra poucas empresas que possuem todos os dados ao longo do período estudado. E quando uma empresa apresentava mais de uma classe de ações, escolheu-se aquela de maior liquidez.

Na diferenciação do nível de exigência de divulgação das informações contábeis, esta amostra total de 75 empresas foi dividida em 2 grupos. O primeiro grupo foi composto pelas empresas que estão listadas no segmento Novo Mercado da BM\&FBOVESPA, totalizando 50 empresas, que estão listadas nas Tabelas 4 e 5 que se encontram no apêndice. O outro grupo de empresas, que estão listadas na Tabela 3 que se encontra no apêndice, ficou composto por 25 entidades.

\subsection{Variáveis Analisadas:}

Ambos índices analisados estão baseados em Matarazzo (2003). O retorno contábil do lucro sobre o patrimônio líquido $\left(\mathrm{ROE}_{\mathrm{it}}\right)$ da empresa $i$, no trimestre $t$, foi calculado pela seguinte formula:

$$
R O E_{i t}=\frac{L L_{i t}}{\left(P L_{i t}+P L_{i(t-1)}\right) / 2}
$$

Em que, $\mathrm{LL}_{\mathrm{it}}$ é o lucro líquido da empresa $i$ no trimestre $t$, e $\mathrm{PL}_{\mathrm{it}}$ é o patrimônio líquido da empresa $i$ no trimestre $t$. Já o retorno de mercado das ações $\operatorname{RET}_{\mathrm{it}}$, da empresa $i$, no trimestre $t$, foi calculado como se segue:

$$
R E T_{i t}=\frac{P_{i t}-P_{i t-1}}{P_{i t-1}}
$$

Em que, $\mathrm{P}_{\mathrm{it}}$ é o preço médio trimestral da ação mais líquida da empresa $i$ no trimestre $t$.

\section{RESULTADOS}

Nas Tabelas 4 e 5 no apêndice, apresentam-se os P-valores do teste de Granger entre as variáveis com suas respectivas defasagens para cada empresa pertencente ao Novo Mercado. Ao nível de 5\% de significância estatística, das 50 ações, 24 apresentaram a causalidade de Granger no sentido do retorno contábil (ROE) para o retorno do mercado (RET) - o que representa 
$48 \%$ do total - e 26 apresentaram significância estatística no sentido inverso, isto é, RET causa ROE - o que representa 52\% do total. No mesmo nível, 17 empresas apresentaram causalidade bilateral - o que representa $34 \%$ do total.

Já na Tabela 3 no apêndice, é evidenciado os P-valores do teste de Granger entre as variáveis com suas respectivas defasagens para cada empresa pertencente ao Mercado Tradicional. Ao nível de 5\% de significância estatística, das 25 ações, 8 apresentaram a causalidade de Granger no sentido do retorno contábil (ROE) para o retorno do mercado (RET) - o que representa 32\% do total - e 10 apresentaram significância estatística no sentido inverso, isto é, RET causa ROE o que representa $40 \%$ do total. No mesmo nível, 4 empresas apresentaram causalidade bilateral - o que representa $16 \%$ do total.

Com base nestes resultados, verifica-se que em boa parte das empresas conseguese evidenciar a causalidade de Granger em algum sentido para as variáveis propostas. Para aprofundar nesta análise, optou-se por fazer uma análise mais detalhada dos resultados visando obter um nível de significância global para a amostra, usando um procedimento similar aos usados por O'Hanlon (1991) e Costa Jr, Meurer, e Cupertino (2007). Nas Tabelas 1 e 2 são evidenciados os parâmetros das distribuições de probabilidade para cada uma das séries de P-valores calculados a partir da amostra.

Considerando como hipótese nula a não existência de causalidade entre as variáveis, esperar-se-ia que a distribuição dos P-valores fosse descrita por uma distribuição normal uniforme com média 0,5 e com extremos 0 e 1 . Porém, ao se observar os parâmetros da distribuição dos P-valores na Tabela 1, para a coluna "ROE causa RET", verifica-se que tanto a média quanto a mediana apresentam valores abaixo de 0,5 , o que é um indício de que o retorno contábil causa, no sentido de Granger, o retorno de mercado. Assim também ocorre na coluna "RET causa ROE". Por isso, para poder concluir cientificamente sobre estes indícios, faz-se o procedimento descrito a seguir.

Na parte inferior da Tabela 1 é apresentada a distribuição das freqüências para cada um dos conjuntos de valores $\mathrm{P}$, apresentando também os valores do teste Shapiro - Wilk, em que se verifica pela hipótese nula de que cada uma das distribuições de freqüência é uma distribuição é normal.

Verifica-se, considerando o valor inferior a 1\% de significância estatística que as séries não seguem uma distribuição normal. Esse resultado demonstra que em nível agregado os retornos contábeis causam, no sentido de Granger, os retornos de mercado e que também os retornos de mercado causam, no sentido de Granger, os retornos contábeis.

Como foi demonstrado que a distribuição das variáveis não segue uma distribuição normal, é necessário usar o teste não paramétrico de Mann -Whitney para verificar a hipótese nula de que as duas populações de valores $\mathrm{P}$ possuem a mesma mediana. O resultado do teste evidenciou um P-valor de 0,8022 , o que nem considerando um valor de significância estatística de $10 \%$ pode-se rejeitar a hipótese nula. Ou seja, as medianas das populações de P-valores para "ROE causa RET" e "RET causa ROE" não são estatisticamente diferentes, evidenciando assim, que a nível agregado a causalidade é bilateral.

Este resultado é diferente do encontrado por Costa Jr, Meurer, e Cupertino (2007) e Carvalhal (2010) que são estudos também feitos com amostra brasileira. Tal divergência possivelmente é explicada pelo número de defasagens usado e pelo número maior de observações consecutivas e sincrônicas que minimizaram o viés de sobrevivência neste presente estudo, o que concede maior significância para os resultados encontrados, apesar de aplicado apenas na amostra pesquisada. 
Tabela 1: Distribuições das probabilidades dos P-valores para ROE e RET

\begin{tabular}{c|c|c}
\hline & ROE causa RET & RET causa ROE \\
\hline Média & 0.149 & 0.168 \\
\hline Mediana & 0.067 & 0.066 \\
\hline \multicolumn{2}{c|}{ Distribuição de frequência des valores P-valores } \\
\hline $0,0-0,199$ & 49 & 54 \\
\hline $0,2-0,399$ & 18 & 8 \\
\hline $0,4-0,599$ & 7 & 7 \\
\hline $0,6-0,799$ & 1 & 6 \\
\hline $0,8-1,0$ & 0 & 0 \\
\hline Total & 75 & 0.000 \\
\hline P-valor (Shapiro-Wilk) & 0.000 & \\
\hline P-valor (Mann-Whitney) & & 0.8022 \\
\hline
\end{tabular}

Fonte: Resultados da pesquisa.

Para verificar o objetivo principal desta pesquisa, buscou-se identificar se o retorno contábil (ROE) das empresas pertencentes ao Novo Mercado da BM\&FBOVESPA tem maior causalidade com os retornos de mercador do que das empresas pertencentes ao Mercado Tradicional.

Analisando a Tabela 2 verifica-se que a média do P-valor para as empresas do Novo Mercado (0.133) é inferior à do Mercado Tradicional $(0,181)$, o que a princípio, indica que o ROE daquelas empresas tem maior capacidade de previsão do RET do que destas. Seguindo esta evidência, pela análise da mediana, tal capacidade de previsão permanece, com as empresa do Novo Mercado $(0,053)$ possuindo maior causalidade aparente do que a do Mercado Tradicional $(0,148)$. Todos estes valores são evidenciados na Tabela 2 .

Tabela 2: Estatísticas dos P-valores para ROE causa RET para os dois grupos.

\begin{tabular}{l|c|c}
\hline & Novo Mercado & Mercado Tradicional \\
\hline Média & 0,133 & 0,181 \\
\hline Mediana & 0,053 & 0,148 \\
\hline Mínimo & 0,000 & 0,000 \\
\hline Máximo & 0,761 & 0,540 \\
\hline Desvio Padrão & 0,177 & 0,174 \\
\hline Moda de defasagem & 4 & 4 \\
\hline P-valor (Mann-Whitney) & \multicolumn{2}{c}{0,1125} \\
\hline
\end{tabular}

Fonte: Resultados da pesquisa.

Visando comprovar tal sinalização, foi feito o teste de Mann-Whitney para verificar se as medianas destas duas séries são estatisticamente diferentes. Esse é um teste não paramétrico, já que como demonstrado na Tabela 1, a distribuição das probabilidades não é normal. E, pela análise deste teste verificou-se, com até $10 \%$ de significância estatística, a não rejeição da hipótese nula, demonstrando que as medianas destas duas distribuições não são estatisticamente diferentes, significando, deste modo, que as informações contábeis dos lucros líquidos das empresas que possuem maior exigência de divulgações não possuem maior causalidade com os retornos de mercado. 


\section{CONCLUSÕES}

O objetivo deste artigo foi verificar o relacionamento entre as séries trimestrais dos lucros contábeis (ROE) e os retornos de mercado (RET) de empresas brasileiras com ações na BM\&FBOVESPA que apresentam níveis diferentes de exigências de divulgação contábil. Para verificar tal relação, aplicou-se o teste de causalidade de Granger (1969) em uma amostra de 75 empresas no período de 1995 à 2010.

Verificou-se, ao nível de 5\% de significância estatística, que boa parte das empresas apresentou pelo menos algum sentido de causalidade, ou do ROE para o RET, ou do RET para o ROE. Para solidificar estes achados foi feita a análise de distribuição da freqüência dos P-valores encontrados em nível agregado.

Pela análise em nível agregado da causalidade entre ROE e RET, pode-se concluir que há causalidade, no sentido de Granger, em ambas as direções. Tal conclusão é baseada no resultado do teste de Shapiro-Wilk que demostrou que as distribuições não são normais, sendo o valor da média estatisticamente menor do que seria a média na distribuiçao normal; e pelo teste não paramétrico de Mann-Whitney, que evidenciou que as medianas das duas distribuições não são estatisticamente diferentes, demonstrando que nenhuma variável exerce maior causalidade que a outra. Isto evidência que o mercado brasileiro de ações pode possuir ineficiência de mercado na forma semi-forte, já que o lucro contábil possui poder de previsão dos retornos das ações.

Os resultados encontrados sobre a causalidade entre ROE e RET coincidem com os resultados encontrados por Costa Jr, Meurer, e Cupertino (2007), e Carvalhal (2010) no que diz respeito a não diferenciação estatística das medianas, e diverge na análise da distribuição normal dos P-valores encontrados. Já os resultados dos trabalhos de O’Hanlon (1991) e Mahmood e Fatah (2007) são semelhantes aos encontrados nesta presente pesquisa no que se refere a causalidade bidirecional dessas variáveis.

$\mathrm{Na}$ análise do objetivo principal deste presente artigo foi verificado se a causalidade entre ROE e RET é maior para empresas que possuem maior nível de exigência de divulgações das informações contábeis. Pela análise do teste de Mann-Whitney verificou-se com até 10\% de significância estatística que as medianas destas duas distribuições não são estatisticamente diferentes, concluindo assim, que os lucros líquidos das empresas que divulgam mais informações contábeis não possuem maior causalidade com o retorno de mercado do que as demais empresas. Com isso, pode-se concluir, de forma geral, através de todos estes resultados, que apesar da importância das informações contábeis para o mercado de ações, a maior qualidade destas informações não gerou maior capacidade preditiva dos retornos do mercado.

Os resultados e as conclusões desta pesquisa estão restritos à amostra analisada, focado nas informações que foram disponibilizadas ao mercado. Como sugestão para futuras pesquisas recomenda-se a realização do teste de causalidade de Granger com outras variáveis relacionadas aos retornos de mercado.

\section{REFERÊNCIAS BIBLIOGRÁFICAS.}

BALL, R. \& BROWN, P. (1968). An empirical evaluation of accounting income numbers. Journal of Accounting Research, 6(2):159-178. 
BAR-YOSEF, S.; CALLEN, J. F.; LIVNAT, J. (1987). Autoregressive Modeling of EarningsInvestment Causality. The Journal of Finance. vol. XLII, no. 1 Mar 1987.

BATISTELA, F. D; CORRAR, L. J; BERGMANN, D.R. \& AGUIAR, A. B. Retornos de Ações e Governança Corporativa: Um Estudo de Eventos. $4^{\circ}$ Congresso USP de Controladoria e Contabilidade. São Paulo. 2004.

BEAVER,W. H. (1968). The information content of annual earnings announcements.

Journal of Accounting Research, 6(2):67-92.

CARVALHAL, R. B. D. Causalidade Entre os Retornos Contábeis e os Retornos do Mercado de Ações Brasileiro. XXXIV Encontro da ANPAD. Rio de Janeiro. 2010.

CARVALHO, A. G. de. Efeitos da migração para os níveis de governança da Bovespa.

Trabalho preparado para a Bovespa, São Paulo, 2003.

COSTA, F.M.; COSTA, A.C.O. \& LOPES, A.B. Conservadorismo em cinco países da América do Sul. Revista de Contabilidade \& Finanças da Universidade de São Paulo, São Paulo, n.41, p.7-19, maio/ago. 2006.

COSTA Jr, N. C. A; MEURER, R \& CUPERTINO, C.M. Existe Alguma Relação entre Retornos Contábeis e Retornos do Mercado de Ações no Brasil? Revista Brasileira de Finanças 2007 Vol. 5, No. 2, pp. 233-245 C 2004 Sociedade Brasileira de Finanças

FAMA, E.F. Efficient Capital Markets: A Review of Theory and Empirical Work. Journal of Finance, volume 25: Maio 1970, pp. 383-417. . (1991). Efficient capital markets: II. Journal of Finance, 46(5):1575- 1617.

GALDI, F. C. \& LOPES, A. B. Relação de longo prazo e causalidade entre o lucro contábil e o preço das ações: evidências do mercado latino-americano. Revista de Adimistração., São Paulo, v.43, n.2, p.186-201, abr./maio/jun. 2008

GRANGER, C. W. J. (1969). Investigating casual relations by econometric models and cross-spectral methods. Econometrica, 37(3):424-438.

GUJARATI, Damodar N. Econometria Básica. 4ª edição. Makron Books do Brasil Editora Ltda. São Paulo. 2006.

HAUGEN, R.A. Modern Investment Theory. 5 ed. Nova Jersey: Prentice-Hall, 2001.

JINDRICHOVSKA, I. The relationship between accounting numbers and returns: some empirical evidence from the emerging market of the Czech Republic. The European Accounting Review. 10:1, 107-131. 2001.

MATARAZZO, D. C. Analise financeira de balanços: abordagem básica e gerencial. 6. ed. São Paulo: Atlas, 2003.

MARTIKAINEN, T. \& PUTTONEN V. Dynamic linkages between stock prices, accrual earnings and cash flows: a cointegration analysis. Annals of Operations Research, 45, 1993. 319-332

MAHMOOD, W. M. W. \& FATAH, F. S. A. Multivariate Causal Estimates of Dividend 
Yields, Price Earning Ratio and Expected Stock Returns: Experience from Malaysia. 15th Annual Conference on Pacific Basin Finance, Economic, Accounting and Management in Equatorial Hotel, Ho Chi Minh City, Vietnam on the 20 -21st July, 2007

O'HANLON, J. The relationship in time between annual accounting returns and annual stock market returns in the U.K. Journal of Business Finance and Accounting, 18(3). (1991).

OHLSON, J.A. Earnings, book values and dividends in equity valuation. Contemporary Accounting Research, Canada, v.11, n.2, p.661-687, Spring 1995.

\& JUETTNER-NAUROTH, B.E. Expected EPS and EPS growth as determinants of value. Review of Accounting Studies, The Netherlands, v.10, p.349-365, 2005.

PINDYCK, R.S. \& RUBINFELD, D.L. Econometria: Modelos e previsões. 4 ed. Rio de Janeiro: Ed. Campos. 2004.

SANTANA, M. H. O novo mercado e a governança corporativa. Revista da CVM, no 34 , janeiro de 2002, p.4-8.

WATTS, R. L.; ZIMMERMAN, J. L. Positive accounting theory. Englewood Cliffs, N.J.: Prentice-Hall. 1986. 


\section{APÊNDICE}

Tabela 3: Valores-P das causalidades entre ROE e RET para as empresas não pertencentes ao Novo Mercado.

\begin{tabular}{|l|c|c|c|c|}
\hline \multicolumn{1}{|c|}{ Empresa } & ROE causa RET & Defasagens & RET causa ROE & Defasagens \\
\hline AES Alpa ON & 0.000 & 2 & 0.511 & 1 \\
AES Tiete PN & 0.067 & 4 & 0.592 & 3 \\
AMbev & 0.371 & 3 & 0.000 & 4 \\
Brasil Telec PN & 0.197 & 4 & 0.166 & 4 \\
Cemar ON & 0.057 & 4 & 0.010 & 1 \\
Coelce PNA & 0.000 & 4 & 0.349 & 3 \\
Comgas PNA & 0.148 & 4 & 0.658 & 1 \\
Contax PN & 0.540 & 3 & 0.026 & 2 \\
Coteminas PN & 0.068 & 4 & 0.078 & 3 \\
Emae PN & 0.046 & 4 & 0.024 & 2 \\
Embratel Part PN & 0.148 & 3 & 0.043 & 3 \\
Forjas Taurus ON & 0.033 & 3 & 0.021 & 4 \\
Lojas Amerc PN & 0.461 & 3 & 0.284 & 2 \\
Metal Leve PN & 0.003 & 4 & 0.000 & 4 \\
Petrobras PN & 0.268 & 3 & 0.005 & 3 \\
Sanepar PN & 0.137 & 1 & 0.579 & 1 \\
Sid Nacional ON & 0.538 & 2 & 0.206 & 1 \\
Souza Cruz ON & 0.018 & 4 & 0.009 & 3 \\
Tele Nort CI PN & 0.018 & 4 & 0.548 & 1 \\
Telemar PN & 0.029 & 1 & 0.673 & 1 \\
Telemar N L PNA & 0.427 & 4 & 0.286 & 1 \\
Telesp PN & 0.208 & 4 & 0.119 & 2 \\
Tim Part S/A PN & 0.332 & 1 & 0.081 & 3 \\
Valefert PN & 0.217 & 4 & 0.082 & 1 \\
Vivo PN & 0.202 & 2 & 0.001 & 3 \\
\hline
\end{tabular}


Tabela 4:Valores-P das causalidades entre ROE e RET para as empresas do Novo Mercado. $\left(1^{\circ}\right.$ parte $)$

\begin{tabular}{|l|c|c|c|c|}
\hline \multicolumn{1}{|c|}{ Empresa } & ROE causa RET & Defasagens & RET causa ROE & Defasagens \\
\hline Alpargatas PN & 0.014 & 1 & 0.168 & 2 \\
Braskem PNA & 0.280 & 2 & 0.650 & 2 \\
BRF Foods ON & 0.000 & 4 & 0.000 & 4 \\
CCR Rodovias ON & 0.761 & 4 & 0.001 & 2 \\
Cemig PN & 0.305 & 4 & 0.453 & 2 \\
Cia Hering ON & 0.067 & 4 & 0.270 & 4 \\
CPFL Energia ON & 0.003 & 4 & 0.041 & 4 \\
Confab ON & 0.271 & 4 & 0.020 & 3 \\
Copel PNB & 0.076 & 4 & 0.015 & 4 \\
Csu Cardsystem ON & 0.000 & 4 & 0.005 & 4 \\
Cyrela Realty ON & 0.050 & 3 & 0.002 & 4 \\
Dasa ON & 0.234 & 1 & 0.385 & 1 \\
Eletropaulo PNB & 0.515 & 1 & 0.079 & 4 \\
Embraer ON & 0.115 & 2 & 0.000 & 2 \\
Energias BR ON & 0.010 & 3 & 0.640 & 4 \\
\hline
\end{tabular}


Tabela 5:Valores-P das causalidades entre ROE e RET para as empresas do Novo Mercado. ( $2^{\circ}$ parte)

\begin{tabular}{|c|c|c|c|c|}
\hline Empresa & ROE causa RET & Defasagens & RET causa ROE & Defasagens \\
\hline Eternit ON & 0.261 & 4 & 0.000 & 3 \\
\hline Fras-Le PN & 0.002 & 4 & 0.000 & 1 \\
\hline Gafisa ON & 0.054 & 3 & 0.124 & 2 \\
\hline Gerdau PN & 0.274 & 4 & 0.033 & 3 \\
\hline Gerdau Met PN & 0.275 & 3 & 0.000 & 4 \\
\hline Grendene PN & 0.004 & 4 & 0.004 & 4 \\
\hline Klabin S/A PN & 0.316 & 4 & 0.155 & 1 \\
\hline Light S/A ON & 0.012 & 4 & 0.001 & 4 \\
\hline Localiza ON & 0.000 & 4 & 0.000 & 4 \\
\hline Lojas Renner ON & 0.016 & 4 & 0.000 & 4 \\
\hline M. Diasbranco ON & 0.000 & 3 & 0.000 & 4 \\
\hline Mangels Indl PN & 0.000 & 4 & 0.023 & 4 \\
\hline Marcopolo PN & 0.359 & 4 & 0.048 & 3 \\
\hline Natura ON & 0.064 & 4 & 0.170 & 3 \\
\hline Net PN & 0.028 & 4 & 0.066 & 4 \\
\hline Odontoprev ON & 0.012 & 4 & 0.163 & 3 \\
\hline OHL Brasil ON & 0.022 & 4 & 0.004 & 3 \\
\hline P. Acucas-Cbd PNA & 0.242 & 4 & 0.151 & 4 \\
\hline Profarma ON & 0.000 & 4 & 0.000 & 4 \\
\hline Randon Part PN & 0.177 & 3 & 0.003 & 4 \\
\hline Rodobensimob ON & 0.000 & 4 & 0.000 & 4 \\
\hline Rossi Resid ON & 0.521 & 1 & 0.604 & 3 \\
\hline Sabesp ON & 0.106 & 3 & 0.076 & 4 \\
\hline Suzano Papel ON & 0.020 & 2 & 0.531 & 4 \\
\hline Tam S/A PN & 0.000 & 4 & 0.010 & 4 \\
\hline Totvs ON & 0.024 & 4 & 0.252 & 3 \\
\hline Tractebel ON & 0.000 & 3 & 0.000 & 2 \\
\hline Tran Paulist PN & 0.257 & 3 & 0.783 & 3 \\
\hline Tupy ON & 0.009 & 4 & 0.025 & 4 \\
\hline Ultrapar PN & 0.414 & 3 & 0.591 & 3 \\
\hline Unipar PN & 0.107 & 4 & 0.344 & 4 \\
\hline Uol PN & 0.052 & 3 & 0.132 & 4 \\
\hline Usiminas PNA & 0.101 & 2 & 0.083 & 2 \\
\hline Vale PNA & 0.234 & 1 & 0.084 & 4 \\
\hline Valid ON & 0.001 & 4 & 0.066 & 4 \\
\hline
\end{tabular}




\section{DADOS DOS AUTORES:}

\section{OCTÁVIO VALENTE CAMPOS}

Universidade Federal de Minas Gerais, Faculdade de Ciências Econômicas, Departamento de Ciências Contábeis.

Av. Antônio Carlos, 6627 -Pampulha

31270-901 - Belo Horizonte, MG - Brasil

\section{WAGNER MOURA LAMOUNIER}

Universidade Federal de Minas Gerais, Faculdade de Ciências Econômicas, Departamento de Ciências Contábeis.

Av. Antônio Carlos, 6627 - Pampulha

31270-901 - Belo Horizonte, MG - Brasil

\section{VALÉRIA GAMA FULLY BRESSAN}

Universidade Federal de Minas Gerais, Faculdade de Ciências Econômicas, Departamento de Ciências Contábeis.

Av. Antônio Carlos 6627, FACE, sala 2041 - Pampulha

31270-901 - Belo Horizonte, MG - Brasil 